\title{
PELATIHAN PERANCANGAN ROBOT BERODA DENGAN DETEKTOR TEPI MEJA PADA SEKOLAH SMA TARSISIUS 1 DAN SMA TRI RATNA
}

\author{
Joni Fat ${ }^{1}$, Wahidin Wahab ${ }^{2}$, dan Wati A. Pranoto ${ }^{3}$ \\ ${ }^{1}$ Program Studi Teknik Elektro, Universitas Tarumanagara Jakarta \\ Email: jonif@ft.untar.ac.id \\ 2 Program Studi Teknik Elektro, Universitas Tarumanagara Jakarta \\ ${ }^{3}$ Program Studi Teknik Sipil, Universitas Tarumanagara Jakarta
}

\begin{abstract}
Wheeled robot is a robot which movement is managed by the rotation of Direct Current (DC) motors. These motors are connected to wheels. Wheeled robot usually is used as a teaching module and as an introduction in robotics. The wheeled robot which we designed is a robot module which moves automatically on a top of a table. This robot is equipped with infrared sensor and ultrasonics sensor. These sensors will prevent the robot from falling down from the edge of the table. They also will be used to avoid obstacles. This robot operates in 7.4 VDC as an operating voltage for DC motors, and uses 9 VDC as an operating voltage microcontroller. The robot is designed as a few modules, i.e. interfacing module for power, sensors and actuators, module for actuators driver, infrared sensor module, ultrasonics sensor module, power supply module, microcontroller module, DC motors module, and robotics platform. The intention for designing this robot is as extracurricular modules for teaching. It is targeted junior high schoollers. All of the modules could be connected to form a wheeled robot for the teaching purpose. The modules are designed using a knock down model so they will be easy to assembly. The platform of this robot is made of acrylic with $3 \mathrm{~mm}$ widths. This acrylic is formed and cut using a laser cutting equipment. The robot creation is recorded and uploaded to youtube.com. Students could have an easier access to the learning modules because they are available online. Students could easily to repeat the modules if the students would like.
\end{abstract}

Keywords: wheeled robot, detector, table edge, teaching module.

\begin{abstract}
ABSTRAK
Robot beroda merupakan robot yang pergerakkannya diatur oleh arah putaran motor direct current (DC) yang terhubung dengan roda. Robot beroda biasa digunakan sebagai media pengajaran serta pengenalan tentang robotika. Robot beroda yang dirancang berupa modul robot beroda yang bergerak secara otomatis pada permukaan meja, serta dilengkapi dengan sensor inframerah dan sensor ultrasonik, yang berfungsi untuk menghindari robot terjatuh dari permukaan meja dan dapat menghindari objek. Robot beroda ini beroperasi dengan tegangan $7.4 \mathrm{~V}_{D C}$ sebagai daya untuk penggerak motor $D C$ dan $9 \mathrm{~V}_{D C}$ untuk sumber tegangan mikrokontroler. Robot ini terdiri dari beberapa modul, yaitu modul antarmuka untuk daya, sensor, dan aktuator, modul pengendali aktuator, modul sensor inframerah, modul sensor ultrasonik, modul power supply, modul mikrokontroler, modul motor $D C$, dan rangka dasar robot. Tujuan dari perancangan modul ini adalah sebagai modul pembelajaran ekstrakurikuler siswa sekolah menengah pertama, seluruh modul tersebut akan menjadi bahan ajar yang saling berhubungan sebagai modul pembelajaran dalam membuat robot beroda. Modul pembelajaran ini menggunakan sistem knock down agar mudah dalam perakitannya. Rangka dasar robot ini terbuat dari akrilik dengan ketebalan $3 \mathrm{~mm}$, yang dibentuk dan dipotong menggunakan alat laser cutting. Pembuatan robot direkamkan dan diunggah ke youtube.com sehingga dapat diakses oleh siswa. Dengan demikian, siswa dapat mengakses materi pembelajaran secara online. Siswa juga dapat mengulang materi dengan lebih mudah.
\end{abstract} Kata Kunci: robot beroda, detektor, tepi meja, modul pelatihan.

\section{PENDAHULUAN}

\section{Analisis Situasi}

Perkembangan teknologi saat ini berkembang sangat cepat. Hal ini ditandai dengan dimulai nya revolusi industri keempat. Pada revolusi industri keempat, diperkenalkan berbagai macam konsep baru, diantaranya internet of things (IoT), artificial intelligence (AI), kendaraan tanpa awak, dan big data (Andrianto \& Herliadi, 2014). Dampak positif dimulainya revolusi industri keempat adalah kemajuan berbagai teknologi baru, salah satunya robotika. Di luar negeri, aktivitas dan pekerjaan manusia sudah banyak digantikan oleh robot (Braunl, 2006).

Robot beroda merupakan salah satu media pengajaran yang digunakan untuk memperkenalkan teknologi robotika. Robot beroda adalah robot yang pergerakkannya diatur oleh arah putaran motor direct current $(D C)$ yang terhubung dengan roda (Widianto, 2017). Alasan robot beroda 
dipilih sebagai media pengajaran karena robot beroda tergolong sederhana sehingga akan mudah dipahami oleh siswa sekolah. Pemberian edukasi tentang teknologi robotika diharapkan dapat membantu mendorong ekosistem robotika Indonesia yang kondusif.

Implementasi bidang robotika di Indonesia masih belum masif baik dalam segi infrastruktur maupun layanan publik (Gitakarma, 2015). Salah satu masalah terkait implementasi bidang robotika di Indonesia adalah sumber daya manusia (SDM). Oleh karena itu, edukasi tentang robotika ke sekolah, dari Sekolah Dasar (SD) hingga Sekolah Menengah Atas (SMA), merupakan salah satu solusi untuk mempersiapkan SDM dalam mengimplementasikan teknologi robotika di Indonesia.

SMA Tri Ratna dan SMA Tarsisius 1 bekerja sama dengan Program Studi Teknik Elektro Universitas Tarumanagara untuk mengadakan pelatihan robot beroda. SMA Tri Ratna berlokasi di Jalan Talib I No.35, RT.9/RW.7, Krukut, Taman Sari, West Jakarta City, Jakarta 11140. SMA Tarsisius 1 berlokasi di Jalan KH. Hasyim Ashari No.26, RW.7, Petojo Utara, Kecamatan Gambir, Kota Jakarta Pusat, Daerah Khusus Ibukota Jakarta 10130.

SMA Tri Ratna adalah salah satu sekolah Buddhis yang berlokasi di Jakarta Barat. Karena kurangnya pengetahuan dan pembelajaran tentang robotika serta tidak adanya kegiatan yang berkaitan dengan hal-hal tersebut. Untuk itu, Teknik Elektro Universitas Tarumanagara memberikan solusi kepada SMA Tri Ratna untuk mengadakan pemberian edukasi berupa pelatihan perancangan robot beroda.

\section{Gambar 1}

\section{Foto Gedung SMA Tri Ratna}

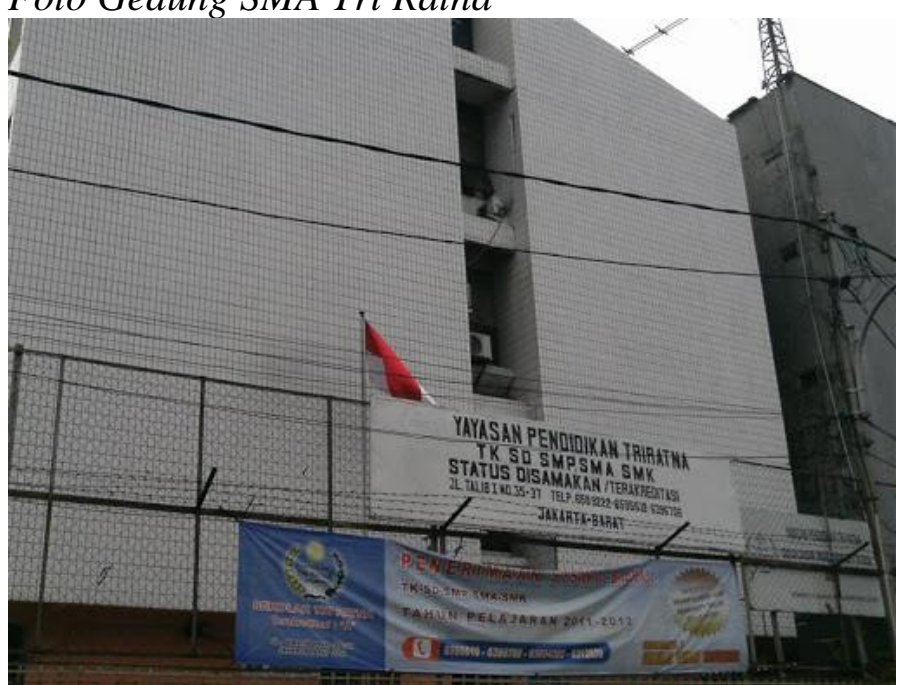

SMA Tarsisius 1 adalah salah satu sekolah dibawah naungan Yayasan Bunda Hati Kudus. Yayasan Bunda Hati Kudus adalah sebuah yayasan pendidikan Katolik yang berada di Jakarta dan menyelenggarakan pendidikan formal mulai dari TK, sekolah dasar, sekolah menengah pertama, dan sekolah menengah atas. Murid SMA Tarsisius 1 memerlukan pemberian edukasi mengenai robotika. Dibutuhkannya pelatihan dikarenakan minimnya pengetahuan dan informasi mengenai teknologi robotika dan implementasinya dalam kehidupan sehari-hari. Dengan pelatihan tersebut, siswa dapat menambah wawasan dan pengetahuan mereka, serta menggali bakat dan menumbuhkan minat dari siswa. 


\section{Gambar 2}

Foto Gedung Sekolah Tarsisius 1

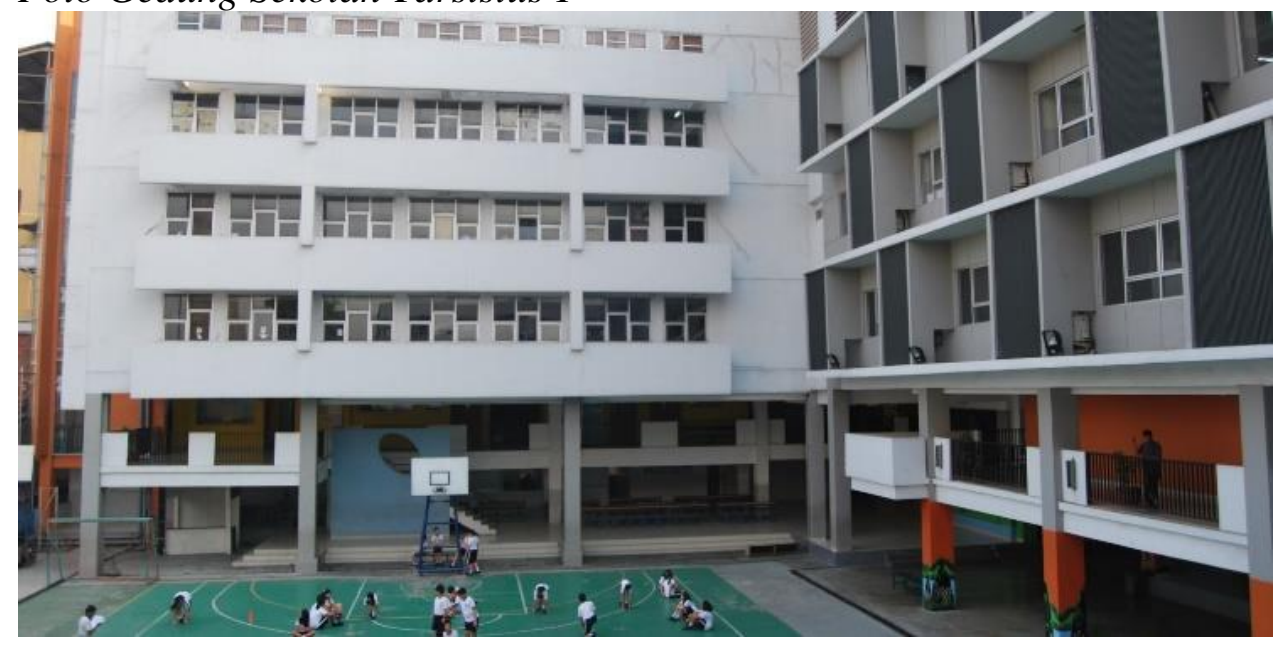

Pemberian pengetahuan dan edukasi berupa pelatihan tentang robotika berupa robot beroda akan dilakukan oleh mahasiswa Teknik Elektro sebagai pengajar dikedua sekolah. Pelatihan akan dilakukan dalam waktu 90 menit. Pelatihan yang akan diadakan adalah merakit robot beroda dari awal hingga dapat beroperasi.

\section{Permasalahan Mitra dan Solusi}

Berdasarkan analisis situasi pada lingkungan mitra maka dapat diketahui permasalahan yaitu, dibutuhkannya pelatihan robot beroda untuk memberikan wawasan dan pengetahuan tentang teknologi robotika kepada siswa. Oleh karena itu, dilakukan program pengabdian kepada masyarakat, dengan didukung kompetensi bidang komputer dan robotika serta elektronika.

Solusi dari permasalahan SMA Tri Ratna dan SMA Tarsisius 1 adalah pemberian edukasi tentang robotika melalui pelatihan dengan materi membuat robot beroda (Jatmiko et al., 2012; Nugroho et al., 2016). Pelatihan ini akan diberikan oleh Program Studi Teknik Elektro Universitas Tarumanagara dengan mahasiswa teknik elektro sebagai pengajarnya. Penyampaian edukasi tentang robotika ini akan diberikan secara daring oleh Program Studi Teknik Elektro Universitas Tarumanagara dengan menyediakan video pelatihan di Youtube. Kemudian link video akan dibagikan kepada siswa SMA Tri Ratna dan SMA Tarsisius 1 khususnya kelas X dan XI. Video yang dipublikasikan ke Youtube bersifat terbuka untuk umum. Pelatihan akan dikemas dalam bentuk video dengan memberikan langkah-langkah membuat robot beroda dari awal hingga akhir.

Materi pelatihan yang dipilih untuk sekolah SMA Tri Ratna dan SMA Tarsisius 1 yaitu robot beroda. Pelatihan robot beroda ini dapat menambah wawasan tentang robotika dan dapat diimplementasikan pada kehidupan sehari - hari. Pelatihan robot beroda ini bertujuan untuk memunculkan ide-ide baru dari siswa sehingga dapat menciptakan terobosan baru dalam dunia teknologi. Robot beroda sendiri menggunakan komponen-komponen sederhana yang memungkinkan untuk pengembangan lebih lanjut. Siswa juga akan diberikan sedikit pengetahuan tentang dasar elektronika dan alat yang akan dipakai selama pelatihan robot beroda ini. pelatihan pembuatan robot beroda ini.

\section{METODE PELAKSANAAN PKM}

Permasalahan utama dari SMA Tarsisius 1 dan SMA Tri Ratna adalah diperlukannya pengenalan serta pelatihan mengenai komponen elektronik dan robotika kepada siswa kelas X dan XI. 
Pelaksanaan pelatihan perancangan robot beroda dengan detektor tepi meja dilakukan secara online melalui video pembelajaran yang dibuat dan dapat dilihat melalui platform Youtube dan akan diikuti 40 siswa masing-masing dari SMA Tarsisius 1 dan SMA Tri Ratna. Pembuatan robot beroda akan dicontohkan oleh pengajar dengan merakit prototype robot beroda yang dijelaskan lewat video yang dibuat. Alat dan bahan yang diperlukan pada pelatihan ini dapat dilihat pada Tabel 1.

\section{Tabel 1}

Alat dan Bahan yang Diperlukan pada Saat Pelatihan

\begin{tabular}{|c|c|c|}
\hline NO. & 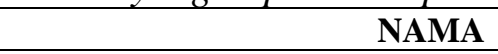 & JUMLAH (PER MODUL) \\
\hline 1. & Arduino NANO & $1 \mathrm{pcs}$ \\
\hline 2. & Proximity infrared sensor & $4 \mathrm{pcs}$ \\
\hline 3. & Ultrasonic sensor & $3 \mathrm{pcs}$ \\
\hline 4. & Baterai 18650 & $2 \mathrm{pcs}$ \\
\hline 5. & Baterai 9V & $1 \mathrm{pcs}$ \\
\hline 6. & Soket baterai 9V & $1 \mathrm{pcs}$ \\
\hline 7. & Soket baterai 18650 & $1 \mathrm{pcs}$ \\
\hline 8. & Motor $D C$ & 4 pcs \\
\hline 9. & Switch & $1 \mathrm{pcs}$ \\
\hline 10. & Project Circuit Board & $1 \mathrm{pcs}$ \\
\hline 11. & Motor Driver L298N & $1 \mathrm{pcs}$ \\
\hline 12. & Baut dan mur & 1 pak \\
\hline 13. & Kabel kawat & 1 pak \\
\hline 14. & Kabel Jumper female to female & 2 pak \\
\hline 15. & Rangka robot akrilik & 1 set \\
\hline 16. & Selang bakar $3 \mathrm{~mm}$ & $1 \mathrm{pcs}$ \\
\hline 17. & Glue gun & $1 \mathrm{pcs}$ \\
\hline
\end{tabular}

\section{Jadwal Pelaksanaan}

Mitra yang bekerja sama dengan Program Studi Teknik Elektro Universitas Tarumanagara untuk kegiatan Pengabdian Masyarakat ini adalah Sekolah SMA Tarsisius I dan SMA Tri Ratna. Pelaksanaan kegiatannya dilakukan dengan:

\section{Mitra 1: SMA Tarsisius I}

1. Peserta Jumlah : 40 siswa/siswi dari kelas X/XI

2. Tempat/Lokasi : Jl. KH. Hasyim Ashari No.26, Petojo Utara,

Kecamatan Gambir,

Kota Jakarta Pusat, Daerah Khusus Ibukota Jakarta 10130.

3. Waktu Kegiatan : Agustus 2020

Mitra 2: SMA Tri Ratna

1. Peserta Jumlah : 40 siswa/siswi dari kelas X/XI

2. Tempat/Lokasi : Jl. Talib Raya No.35, RT.9/RW.7

Krukut, Taman Sari, West Jakarta City, Jakarta 11140.

3. Waktu Kegiatan : Agustus 2020

\section{HASIL DAN PEMBAHASAN}

Kegiatan pelatihan perancangan robot beroda dengan detektor tepi meja kepada mitra telah selesai dilakukan. Adapun yang telah dilakukan yaitu pemberian edukasi tentang robotika melalui video pembelajaran pembuatan robot beroda dengan detektor tepi meja yang diunggah pada platform Youtube. Video pembelajaran dapat dilihat pada alamat http://tinyurl.com/RobotBerodaDDTM. 
Adapun target materi yang disampaikan dapat dilihat pada Tabel 2. Gambar 3 memperlihatkan robot beroda, dan Gambar 4 memperlihatkan keseluruhan modul rancangan. Gambar 5 memperlihatkan bentuk akhir dari perakitan. Gambar 6 memperlihatkan pengujian robot dalam mendeteksi ujung meja.

\section{Tabel 2}

Hasil kegiatan pelatihan perancangan robot beroda dengan detektor tepi meja

\begin{tabular}{|c|c|c|c|}
\hline NO. & MITRA & TARGET MATERI & REALISASI PADA VIDEO \\
\hline 1. & SMA Tarsisius I & $\begin{array}{ll}\text { - } & \text { Penjelasan tentang robot } \\
\text { beroda } \\
\text { - }\end{array}$ & $\begin{array}{ll}-\quad & \text { Penjelasan tentang robot } \\
\text { beroda } \\
\text { - }\end{array}$ \\
\hline 2. & SMA Tri Ratna & $\begin{array}{l}\text { Penjelasan tentang robot } \\
\text { beroda } \\
\text { - } \\
\text { Pengenalan arduino nano, } \\
\text { sensor ultrasonik, sensor IR } \\
\text { Merakit modul robot beroda } \\
\text { dengan detektor tepi meja }\end{array}$ & 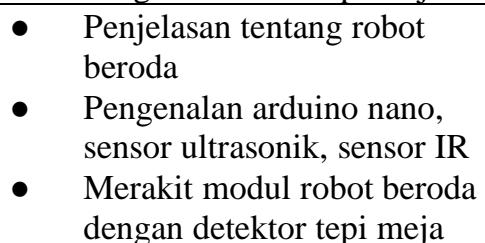 \\
\hline
\end{tabular}

\section{Gambar 3}

\section{Robot Beroda}

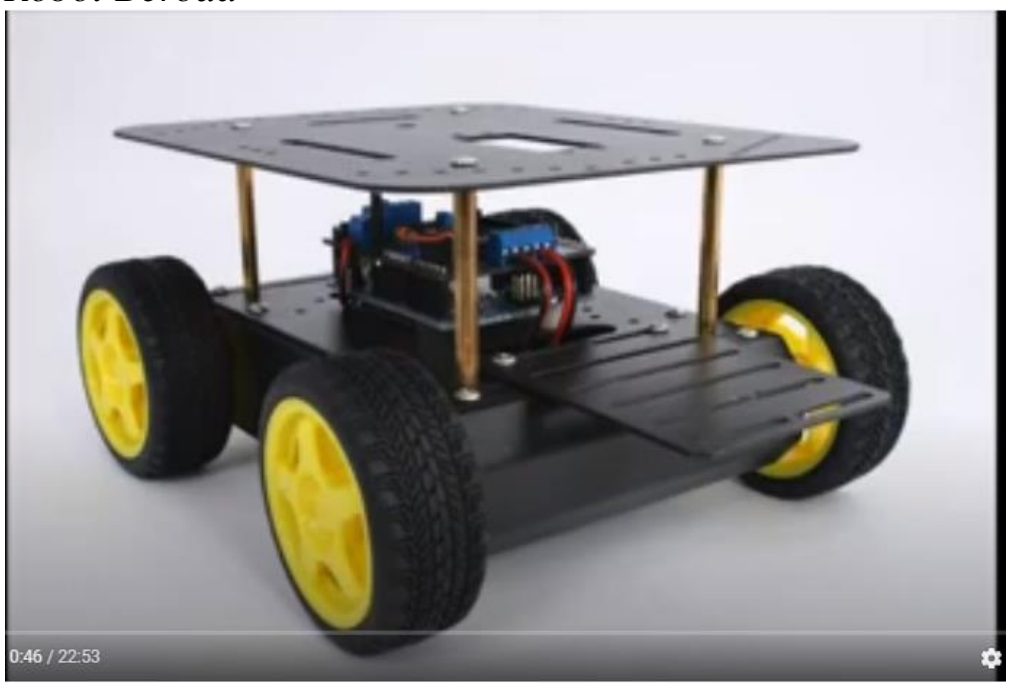

\section{Gambar 4}

Modul dan Peralatan Perancangan Robot

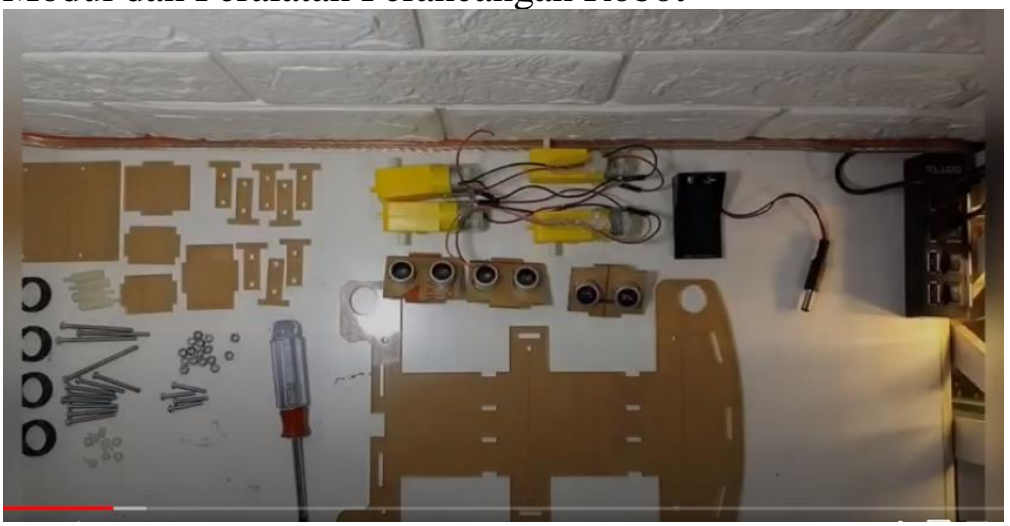




\section{Gambar 5}

\section{Bentuk Akhir Perakitan Robot}

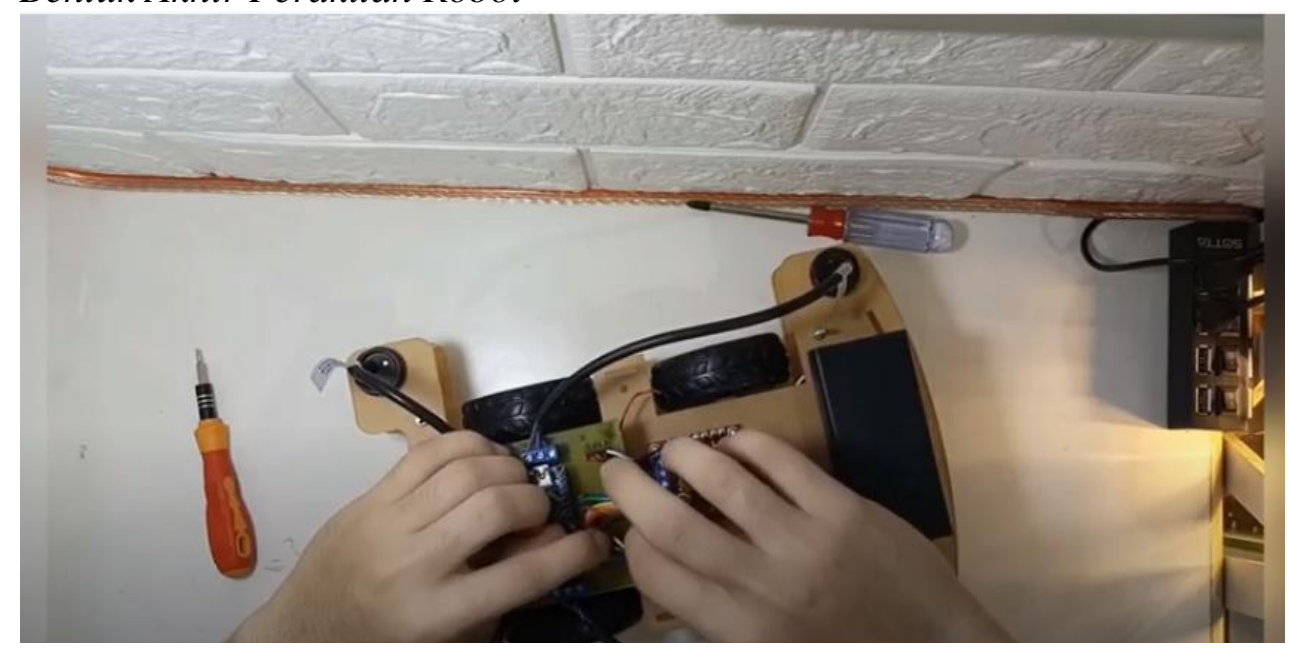

\section{Gambar 6}

Pengujian Robot Mendeteksi Ujung Meja

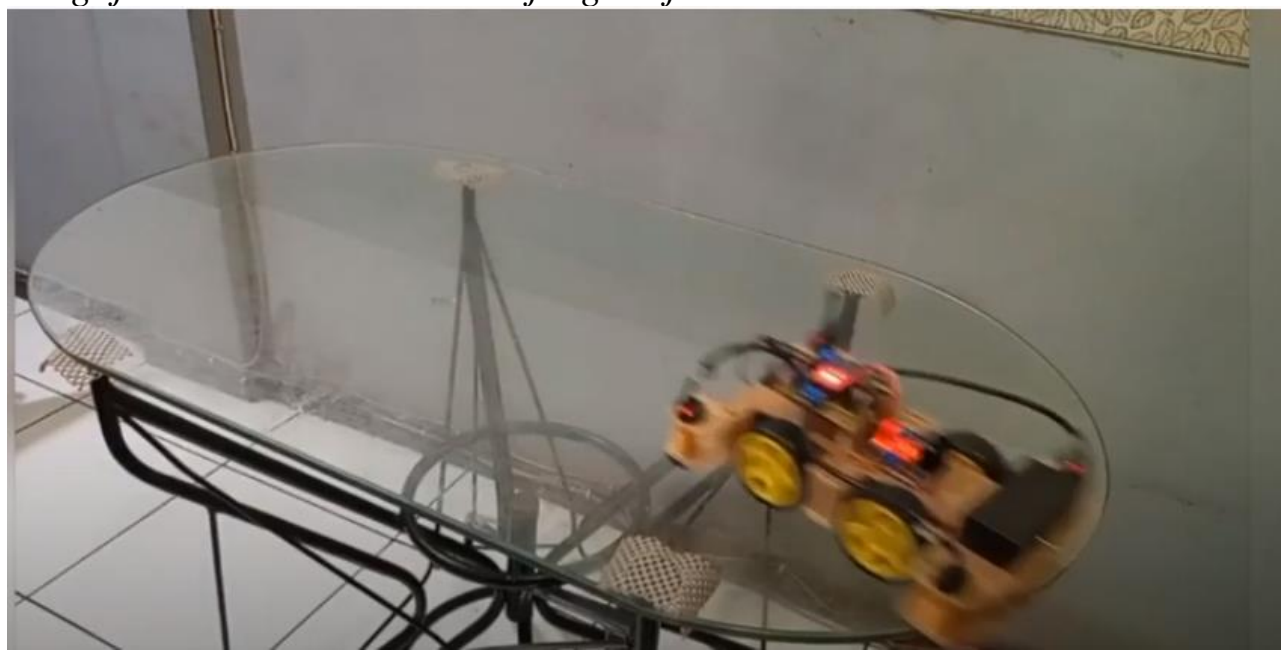

\section{KESIMPULAN DAN SARAN}

Pengajaran menggunakan media video dinilai lebih efisien dan menghemat waktu dalam penyampaian materi dibandingkan dengan pengajaran yang dilakukan secara tatap muka. Pengulangan materi pembelajaran lebih mudah dilakukan melalui pengajaran dengan media video, dikarenakan siswa hanya perlu mengulang video pada bagian materi yang belum dipahami dan tidak perlu menunggu pengajar untuk mengulang materi yang belum dipahami.

Pengajaran secara online sulit untuk menilai kemandirian siswa dalam membuat robot beroda. Materi yang disampaikan masih belum bisa menjangkau semua siswa karena memiliki perbedaan kemampuan dalam memahami materi yang disampaikan melalui video.

\section{REFERENSI}

Andrianto, H., \& Herliadi, R. (2014). Pengendali robot beroda menggunakan smartphone android. TESLA, 16(2). http://dx.doi.org/10.24912/tesla.v16i2.375

Braunl, T. (2006). Embedded robotics: Mobile robot design and applications with embedded system. Springer.

Gitakarma, M. S. (2015). Sistem kendali. Graha Ilmu. 
Jatmiko, W., Mursanto, P., Tawakal, M. I., \& Alvissalim, M. S. (2012). Robotika: Teori dan aplikasi. UI PRESS.

Nugroho, K. A., Kurnianingtyas, M. C. D., \& Pamosoaji, A. K. (2016). Pelatihan pembuatan robot line follower dengan scratch dan arduino di SMP Putra Bangsa, Klaten. Seminar Nasional Pengabdian kepada Masyarakat (pp. 137-147).

Widianto, E. D., Alfianto, U., \& Isnanto, R. (2017). Robot beroda perambat dinding berbasis mikrokontroler ATmega 2560 dilengkapi kendali nirkabel dan penghindar rintangan. Jurnal Teknologi dan Sistem Komputer, 5(2), 49-56. 